\title{
Triterpenoids and Steroid from the Leaves of Callistemon citrinus (Curtis.)
}

\author{
Farhana Ahmed ${ }^{1 \Psi}$, Mohammad Sharifur Rahman ${ }^{1 \Psi}$, \\ Muhammad Abdullah Al-Mansur ${ }^{2}$ and Mohammad A. Rashid ${ }^{1}$ \\ ${ }^{1}$ Phytochemical Research Laboratory, Department of Pharmaceutical chemistry, Faculty of Pharmacy \\ University of Dhaka, Dhaka-1000, Bangladesh \\ ${ }^{2}$ Bangladesh Council of Scientific and Industrial Research (BCSIR), Dr. Qudrat-I-Khuda Road, \\ Dhanmondi, Dhaka-1205, Bangladesh
}

Received: June 15, 2015; Accepted: December 17, 2015; Published (web): February 11, 2016

\begin{abstract}
Three triterpenes a one steroidal glucoside were isolated from the methanolic crude extract and its carbon tetrachloride soluble fraction of the leaves of Callistemon citrinus (Curtis.). The structure of the isolated compounds were established as erythrodiol (1), betulinic acid (2), $\beta$-sitosterol-3-O- $\beta$-D-glucoside (3) and taraxerol (4) by high field NMR analyses. This is the first report of the occurrence of these compounds in C. citrinus growing in Bangladesh.
\end{abstract}

Key words: Callistemon citrinus, Myrtaceae, erythrodiol, betulinic acid, $\beta$-sitosterol-3-O- $\beta$-D-glucoside, taraxerol

\section{INTRODUCTION}

Callistemon citrinus (Curtis.) is an evergreen plant belongs to Myrtaceae family. It is commonly known as Red bottlebrush or Lemon bottlebrush or Crimson bottlebrush. Callistemon species are widely distributed in the wet tropics, notably Australia, South America and tropical Asia, but now available all over the world. ${ }^{1,2} C$. citrinus has been reported to be antibacterial, antifungal and relaxant. ${ }^{3,4}$ Previous phytochemical investigations led to the isolation of 1,8-cineole and $\alpha$-terpineol as major compounds from the leaves and flowers. In addition, nitisinone, isolated from this plant exhibited herbicidal activity. ${ }^{5}$ The current project was undertaken to investigate the secondary metabolites of $C$. citrinus comprehensively and we, herein, report the isolation of erythrodiol (1), betulinic acid (2), $\beta$-sitosterol-3-O- $\beta$-D-glucoside (3) and taraxerol (4) for the first time.

Correspondence to: Mohammad A. Rashid

Tel.: 880-2-9661920, Ext. 8137; Fax: 880-2-9667222;

E-mail: rashidma@du.ac.bd.

${ }^{\Psi}$ These authors have equal contribution

Dhaka Univ. J. Pharm. Sci. 15(1): 1-5, 2016 (June)

\section{MATERIALS AND METHODS}

General: ${ }^{1} \mathrm{H}$ NMR spectra were recorded using a Bruker AMX-400 (400 MHz) instrument. For NMR studies deuterated chloroform and methanol was used and the $\delta$ values of ${ }^{1} \mathrm{H}$ spectra were referenced to the residual non-deuterated solvent signal.

Plant material: The leaves of $C$. citrinus were collected from Dhaka in August, 2013. A voucher specimen for C. citrinus (L.) (DACB accession no38576) has been deposited in Bangladesh National Herbarium, Mirpur, Dhaka.

Extraction and isolation of compounds: The powdered leaves $(1 \mathrm{~kg})$ of $C$. citrinus were extracted with $5 \mathrm{~L}$ methanol at room temperature for 5 days. A portion of the concentrated methanol extract $(5 \mathrm{~g})$ was fractionated by the modified Kupchan partitioning protocol $^{6}$ into petroleum ether, carbon tetrachloride, chloroform and aqueous soluble fractions.

Later, the carbon tetrachloride soluble fraction (300 mg) was subjected to gel permeation chromatography (GPC) over Lipophilic Sephadex (LH-20) soaked in a mixture of $n$-hexanedichloromethane-methanol (2:5:1). The column was 
eluted with the same solvent mixture and finally washed with dichloromethane and methanol mixtures of increasing polarities. The elaute was collected in 25 conical flask, each containing $100 \mathrm{ml}$. Further purification of fractions 10 and 18 by preparative thin layer chromatography (PTLC) over silica gel
(Kieselgel $60 \quad \mathrm{~F}_{254}$ ) using $1.5 \%$ methanol in chloroform yielded erythrodiol (1) (4 mg) as white powder and betulinic acid (2) (6 mg) as white gum, respectively.<smiles>CC1(C)CCC2(CO)CCC3(C)C(=CCC4C5(C)CCC(O)C(C)(C)C5CCC43C)C2C1</smiles><smiles>C=C(C)C1CCC2(C(=O)O)CCC3(C)C(CCC4C5(C)CCC(O)C(C)(C)C5CCC43C)C12</smiles>

1<smiles>CCC(CC[C@@H](C)C1CCC2C3CC=C4CC(OC5O[C@H](O)[C@@H](O)[C@@H](O)[C@H]5O)CC[C@]4(C)C3CCC21C)C(C)C</smiles>

3<smiles>CC1(C)CCC2(C)CC=C3C(C)(CCC4C3(C)CCC3C(C)(C)C(O)CCC43C)C2C1</smiles>

4

A portion of the concentrated methanol extract $(10 \mathrm{~g})$ was also subjected to vacuum liquid chromatography (VLC) over silica gel (Kieselgel 60, mesh 70-230) and the column was eluted with $n$ - hexane, ethyl acetate and ethyl-acetate methanol mixtures of increasing polarities to give a total of 25 
fractions, each $10 \mathrm{ml}$. On the basis of TLC behavior, VLC fractions eluted with $7.5 \%, 10 \%$ and $12 \%$ ethyl acetate in $n$ - hexane were mixed together and again fractionated by GPC using the solvent system mentioned earlier. A total of 20 fractions were collected each containing $5 \mathrm{ml}$. Further purification of sub-fractions 4 and 9 by PTLC over silica gel (Kieselgel $60 \mathrm{~F}_{254}$ ) using $15 \%$ and $20 \%$ ethyl acetate in petroleum ether yielded $\beta$-sitosterol-3-O- $\beta$-Dglucoside (3) $(7 \mathrm{mg})$ as white powder and taraxerol (4) $(8 \mathrm{mg})$ as amorphous mass, respectively.

Erythrodiol (1): White powder; ${ }^{1} \mathrm{H}$ NMR (400 $\left.\mathrm{MHz}, \mathrm{CDCI}_{3}\right): \delta 5.12(1 \mathrm{H}$, br s, H-12), $3.52(1 \mathrm{H}, \mathrm{dd}$, $\left.J=10.4 \mathrm{~Hz}, \mathrm{H}_{\mathrm{b}}-28\right), 3.21\left(1 \mathrm{H}, \mathrm{dd}, J=10.4 \mathrm{~Hz}, \mathrm{H}_{\mathrm{a}}-\right.$ 28), $3.18(1 \mathrm{H}, \mathrm{dd}, J=11.2,5.2 \mathrm{~Hz}, \mathrm{H}-3), 1.10(3 \mathrm{H}, \mathrm{s}$, $\left.\mathrm{H}_{3}-30\right), 0.98$ (3H, s, $\left.\mathrm{H}_{3}-27\right), 0.95$ (3H, s, $\left.\mathrm{H}_{3}-29\right), 0.92$ (3H, s, $\left.\mathrm{H}_{3}-23\right), 0.86\left(3 \mathrm{H}, \mathrm{s}, \mathrm{H}_{3}-26\right), 0.81$ (3H, s, $\mathrm{H}_{3}-$ 25), $0.78\left(3 \mathrm{H}, \mathrm{s}, \mathrm{H}_{3}-24\right)$.

Betulinic acid (2): White gum; ${ }^{1} \mathrm{H}$ NMR (400 $\mathrm{MHz}, \mathrm{CDCI}_{3}$ ): $\delta 4.73$ and 4.58 (each $1 \mathrm{H}$, br s, $\mathrm{H}_{2-}$ 29), 3.17 ( $1 \mathrm{H}, \mathrm{dd}, J=11.0,6.2 \mathrm{~Hz}, \mathrm{H}-3), 2.99$ (lH, m, H-19), 1.68 (3H, s, $\left.\mathrm{H}_{3}-30\right), 0.96$ (3H, s, $\left.\mathrm{H}_{3}-26\right), 0.95$ (3H, s, $\left.\mathrm{H}_{3}-23\right), 0.92\left(3 \mathrm{H}, \mathrm{s}, \mathrm{H}_{3}-27\right), 0.81\left(3 \mathrm{H}, \mathrm{s}, \mathrm{H}_{3}-\right.$ 25), $0.74\left(3 \mathrm{H}, \mathrm{s}, \mathrm{H}_{3}-24\right)$.

$\boldsymbol{\beta}$-sitosterol-3-O- $\boldsymbol{\beta}$-D-glucoside (3): White powder; ${ }^{1} \mathrm{H}$ NMR $\left(400 \mathrm{MHz}, \mathrm{CDCI}_{3}+\mathrm{CD}_{3} \mathrm{OD}\right): \delta$ $5.39(1 \mathrm{H}, \mathrm{s}, \mathrm{H}-6), 4.14\left(1 \mathrm{H}, \mathrm{d}, J=6.8, \mathrm{H}-1^{\prime}\right), 3.57$ (1H, m, H-3), 1.00 (3H, s, $\left.\mathrm{H}_{3}-19\right), 0.91$ (3H, d, $J=6.4$ $\left.\mathrm{Hz}, \mathrm{H}_{3}-21\right), 0.85\left(3 \mathrm{H}, \mathrm{d}, J=7.0 \mathrm{~Hz}, \mathrm{H}_{3}-26\right), 0.83(3 \mathrm{H}$, br s, $\left.\mathrm{H}_{3}-18\right), 0.81$ (3H, br s, $\left.\mathrm{H}_{3}-29\right), 0.67$ (3H, d, $J$ $\left.=8.1 \mathrm{~Hz}, \mathrm{H}_{3}-27\right)$.

Taraxerol (4): Amorphous mass; ${ }^{1} \mathrm{H}$ NMR (400 $\left.\mathrm{MHz}, \mathrm{CDCI}_{3}\right): \delta 5.53(1 \mathrm{H}, J=8.2,3.2 \mathrm{~Hz}, \mathrm{H}-15)$, $3.20 \mathrm{dd}(1 \mathrm{H}, J=11.0,4.7 \mathrm{~Hz}, \mathrm{H}-3), 1.14\left(3 \mathrm{H}, \mathrm{s}, \mathrm{H}_{3}-\right.$ 26), 1.03 (3H, s, $\left.\mathrm{H}_{3}-23\right), 0.98$ (3H, s, $\left.\mathrm{H}_{3}-29\right), 0.97$ (3H, s, $\left.\mathrm{H}_{3}-25\right), 0.91$ (3H, s, H $\left.{ }_{3}-27\right), 0.89\left(3 \mathrm{H}, \mathrm{s}, \mathrm{H}_{3}-\right.$ 30), 0.79 (3H, s, $\left.\mathrm{H}_{3}-28\right), 0.77$ (3H, s, $\left.\mathrm{H}_{3}-24\right)$.

\section{RESULTS AND DISCUSSION}

A total of four compounds were isolated from the leaves of $C$. citrinus. The structures of the isolated compound were deduced by extensive NMR spectral analyses.
The ${ }^{1} \mathrm{H}$ NMR spectrum (400 $\mathrm{MHz}, \mathrm{CDCl}_{3}$ ) of compound 1 displayed a characteristic double doublet at $\delta 3.18(J=11.2,5.2 \mathrm{~Hz})$ indicative of $\mathrm{H}-3$ in a triterpene type carbon skeleton. The downfield broad singlet at $\delta 5.12$ demonstrated an olefinic proton at $\mathrm{H}-12$. The spectrum exhibited two doublets $(J=10.4$ $\mathrm{Hz})$ at $\delta \quad 3.21$ and 3.52 assignable to the hydroxymethyl protons at $\mathrm{C}-28$. The ${ }^{1} \mathrm{H}$ NMR spectrum also showed seven three proton singlets at $\delta$ $0.78\left(\mathrm{H}_{3}-24\right), 0.81\left(\mathrm{H}_{3}-25\right), 0.86\left(\mathrm{H}_{3}-26\right), 0.92\left(\mathrm{H}_{3}-\right.$ 23), $\left.0.95\left(\mathrm{H}_{3}-29\right), 0.98 \mathrm{H}_{3}-27\right)$ and $1.10\left(\mathrm{H}_{3}-30\right)$ demonstrative of seven methyl groups. On this basis, compound 1 was characterized as erythrodiol, the identity of which was confirmed by comparison of the spectral data with previously reported values. ${ }^{7}$

The ${ }^{1} \mathrm{H}$ NMR spectrum (400 $\mathrm{MHz}, \mathrm{CDCl}_{3}$ ) of compound 2 indicated the presence of a lupene skeleton having an angular carboxylic acid group. It displayed signals attributable to an exomethylene group at $\delta 4.58$ and 4.73 (1H each, br. s.), which together with an allylic methyl at $\delta 1.68$ indicated an isopropenyl functionality. The ${ }^{1} \mathrm{H}$ NMR spectrum also showed singlets at $\delta 0.74,0.81,0.92,0.95$ and $0.96(3 \mathrm{H}$ each) suggestive of the presence of five methyl groups in this compound. These were attributed to $\mathrm{H}_{3}-24, \mathrm{H}_{3}-25, \mathrm{H}_{3}-27, \mathrm{H}_{3}-23$ and $\mathrm{H}_{3}-26$, respectively. The double doublet $(J=11.0$ and 6.2 $\mathrm{Hz}$ ) centered at $\delta 3.17$ could be assigned to the oxymethine proton at $\mathrm{C}-3$. The large coupling of this proton (H-3) with the vicinyl methylene protons at $\mathrm{C}$ 2 suggested a $\beta$ (beta) orientation of the hydroxyl group at C-3. In addition, the spectrum also displayed a multiplet at $\delta 2.99$ for the methine proton at C-19. Thus, compound $\mathbf{2}$ was identified as betulinic acid, which was confirmed by comparison of its spectral data with reported values ${ }^{8}$ as well co-TLC with authentic sample.

The ${ }^{1} \mathrm{H}$ NMR spectrum (400 $\mathrm{MHz}, \mathrm{CDCl}_{3}+$ $\mathrm{CD}_{3} \mathrm{OD}$ ) of compound 3 revealed a one proton multiplet at $\delta 3.57$, the position and multiplicity of which was indicative of $\mathrm{H}-3$ of the steroid nucleus. The typical H- 6 of the steroidal skeleton was evident as a multiplet at $\delta 5.39$ that integrated for one proton. The spectrum further revealed signals at $\delta 0.83$ and $\delta$ 
$1.00(3 \mathrm{H}$ each) assignable to two tertiary methyl groups at $\mathrm{C}-13$ and $\mathrm{C}-10$, respectively. The ${ }^{1} \mathrm{H}$ NMR spectrum showed two doublets centered at $\delta 0.67(\mathrm{~J}$ $=8.1 \mathrm{~Hz})$ and $0.85(J=7.0 \mathrm{~Hz})$ which could be attributed to two methyl groups at C-25. The doublet at $\delta 0.91(J=6.4 \mathrm{~Hz})$ was demonstrative of a methyl group at C-20. On the other hand, a broad triplet of three proton intensity at $\delta 0.81$ could be assigned to the primary methyl group attached to C-28. The above spectral features are in close agreement to those observed for $\beta$-sitosterol. ${ }^{9,10}$ Besides, a doublet at $\delta 4.14(J=6.8 \mathrm{~Hz})$ integrated for one proton indicated the presence of an anomeric proton (H-1') of a glucoside moiety. The large coupling constant $(6.8 \mathrm{~Hz})$ of this proton demonstrated the beta $(\beta)$ linkage between the aglycone and glycone moieties. All of these data are in close agreement with the $\beta$ sitosterol-3-O- $\beta$-D-glucoside. ${ }^{10}$ Thus, compound $\mathbf{3}$ was characterized as $\beta$-sitosterol-3-O- $\beta$-D-glucoside. Its identity was also confirmed by co-TLC with authentic sample.

The ${ }^{1} \mathrm{H}$ NMR spectrum $\left(400 \mathrm{MHz}, \mathrm{CDCl}_{3}\right.$ ) of compound 4 revealed eight three proton singlets at $\delta$ $0.77\left(\mathrm{H}_{3}-24\right), 0.79\left(\mathrm{H}_{3}-28\right), 0.89\left(\mathrm{H}_{3}-30\right), 0.91\left(\mathrm{H}_{3}-\right.$ 27), $0.97\left(\mathrm{H}_{3}-25\right), 0.98\left(\mathrm{H}_{3}-29\right), 1.03\left(\mathrm{H}_{3}-23\right)$ and $1.14\left(\mathrm{H}_{3}-26\right)$ which revealed the presence of eight methyl groups in a pentacyclic triterpene. It also showed a double doublet $(J=8.2,3.2 \mathrm{~Hz})$ centered at $\delta 5.53$ which could be assigned to an olefinic proton, H-15. Another double doublet $(J=11.0,4.7 \mathrm{~Hz})$ at $\delta$ 3.20 demonstrated the characteristic oxymethine proton at C-3. The above spectral features are in close agreement to the data observed for taraxerol. ${ }^{11}$ Its identity was also confirmed by co-TLC with authentic sample.

Earlier erythrodiol has been reported to have anti-inflammatory and vasorelaxant activities. ${ }^{12}$ Betulinic acid is reputed to have anticancer and antiHIV activities. ${ }^{13}$ Beta-sitosterol glucoside has been reported to have analgesic, anntihyperglycemic, insulin releasing, etc. properties. ${ }^{14,15}$ Taraxerol has significant anticancer and anti-inflammatory activities. ${ }^{16,17}$ Based on this, the medicinal potential of $C$. citrinus can be expected very diverse.

\section{CONCLUSION}

From the current study, it is evident that $C$. citrinus is rich in medicinally important secondary metabolites. Further biological and chemical studies are required to explore more biological prospectives of this plant as well as obtain bioactive compounds.

\section{ACKNOWLEDGEMENT}

One of us (Mohmmad Sharifur Rahman) acknowledges the University Grants Commission (UGC) of Bangladesh for partial financial support to conduct this research.

\section{REFERRENCES}

1. Stead, T.Y. and Butler, G. 1983. Your Australian Garden, No. 5 - Callistemons and other Bottlebrushes. (D.G. Stead Memorial Wildlife Research Foundation), pp. 408-412.

2. Elliot, W.R. and Jones, D.L. 1982. Encyclopaedia of Australian Plants: Vol 2, (Lothian Publishing Company Pvt. Ltd., Melbourne.).

3. Oyedeji, O., Lawal, O., Shode, F. and Oyedeji, A. 2009. Chemical composition and antibacterial activity of the essential oils of Callistemon citrinus and Callistemon viminalis from South Africa. Molecules 14, 1990.

4. Ali, N., Ahmed, G., Ali Shah, S., Shah, I., Ghias, M. and Khan, I. 2011. Acute toxicity, brine shrimp cytotoxicity and relaxant activity of fruits of Callistemon citrinus curtis. BMC Complement. Altern. Med. 11, 99.

5. Goyal, P.K., Jain, R., Jain, S. and Sharma, A. 2012. A Review on biological and phytochemical investigation of plant genus Callistimon. Asian Pac. J. Trop. Biomed. 2, S1906-S1909.

6. VanWagenen, B.C., Larsen, R., Cardellina, J.H., Randazzo, D., Lidert, Z.C. and Swithenbank, C. 1993. Ulosantoin, a potent insecticide from the sponge Ulosa ruetzleri. J. Org. Chem. 58, 335-337.

7. Aktar, F., Kaisar, M.A., Kabir, A.N.M.H., Hasan, C.M. and Rashid, M.A. 2009. Phytochemical and biological investigations of Ixora arborea Roxb. Dhaka Univ. J. Pharm. Sci. 8, 161-166.

8. Rahman, M.S., Chowdhury, R., Begum, B., Rahman, K.M. and Rashid, M.A. 2005. Phytochemical studies of Amoora cucullata. Dhaka Univ. J. Pharm. Sci. 4, 73-75.

9. Morales, G., Sierra, P., Mancilla, A., Paredes, A., Loyola, L.A., Gallardo, O. and Borquez, J. 2003. Secondary metabolites from four medicinal plants from northern Chile: antimicrobial activity and biotoxicity against Artemia salina. J. Chil. Chem. Soc. 48, 13-18. 
10. Tripathee, H.P., Sharma, R.P., Timilsina, Y.P., Pathak, R. and Devkota, K.P. 2011. An assessment of ethnomedicinal use, chemical constituents analysis and bioactivity evaluation on high altitude medicinal plant Delphinium brunonianum of Manang district. Nepal J. Sci. Tech. . 12, 111-118.

11. Hernández-Chávez, I., Torres-Tapia, L.W., Simá-Polanco, P., Cedillo-Rivera, R., Moo-Puc, R. and Peraza-Sánchez, S.R. 2012. Antigiardial activity of Cupania dentata bark and its constituents. J. Mex. Chem. Soc. 56, 105-108.

12. Rodriguez-Rodriguez, R., Herrera, M.D., Perona, J.S. and Ruiz-Gutierrez, V. 2004. Potential vasorelaxant effects of oleanolic acid and erythrodiol, two triterpenoids contained in 'orujo' olive oil, on rat aorta. Br. J. Nutr. 92, 635-642.

13. Baglin, I., Mitaine-Offer, A.C., Nour, M., Tan, K., Cave, C. and Lacaille-Dubois, M.A. 2003. A review of natural and modified betulinic, ursolic and echinocystic acid derivatives as potential antitumor and anti-HIV agents. Mini. Rev. Med. Chem. 3, 525-539.
14. Villasenor, I.M., Angelada, J., Canlas, A.P. and Echegoyen, D. 2002. Bioactivity studies on beta-sitosterol and its glucoside. Phytother. Res. 16, 417-421.

15. Ivorra, M.D., D'Ocon, M.P., Paya, M. and Villar, A. 1988. Antihyperglycemic and insulin-releasing effects of betasitosterol 3-beta-D-glucoside and its aglycone, betasitosterol. Arch. Int. Pharmacodyn. Ther. 296, 224-231.

16. Yao, X., Li, G., Bai, Q., Xu, H. and Lu, C. 2013. Taraxerol inhibits LPS-induced inflammatory responses through suppression of TAK1 and Akt activation. Int. Immunopharmacol. 15, 316-324.

17. Sharma, K. and Zafar, R. 2015. Occurrence of taraxerol and taraxasterol in medicinal plants. Pharmacogn. Rev. 9, 19-23. 